\title{
2015 INDUCTION OF ASSBI FELLOWS
}

\section{PROFESSOR GLYNDA KINSELLA}

Glynda joined ASSBI in 1980 was on the Executive Committee as President Elect in 2007 and became the President in 2009-2011. She has made a significant and long standing contribution to ASSBI and has also made a distinguished contribution to research in the field of TBI and disorders of ageing, and as an educator of Clinical Neuropsychology.

\section{DR MICHAEL PERDICES}

Michael joined ASSBI in 1983 and has been on the Executive Committee since 1999. His many contributions to the Society include marketing, professional development, conference organisation and overseeing student awards. He has also made a substantial contribution over a sustained period to teaching and research into clinical assessment and treatment methodology in the brain injury field. 